RU Неформальное образование представителей старшего поколения как фактор их активного долголетия

\author{
Гордина О. В., Гордин А. И.
}

\begin{abstract}
Аннотация. Цель исследования - определить психолого-педагогические условия организации неформального образования для представителей старшего поколения, способствующего их активному долголетию. Авторы представили основные подходы к определению понятий «неформальное образование», «третий возраст», «активное долголетие», «андрагогическое взаимодействие», «третичная социализация», «Высшая народная школа». В статье обоснована актуальность организации неформального образования для содействия активному долголетию пожилых людей, выявлена специфика процесса обучения в третьем возрасте, доказана эффективность андрагогического взаимодействия для третичной социализации пожилых людей как основы их активного долголетия. Определены психолого-педагогические условия организации неформального образования для представителей старшего поколения. Научная новизна заключается в разработке организационно-методической системы образования людей пожилого возраста в контексте тенденций развития современного образования и конструирования на этой основе новой образовательной реальности как реализуемого авторского проекта. В результате проведенного исследования подтверждена значимость неформального образования пожилых людей для их долголетия, выявлены психолого-педагогические условия организации данной деятельности. На основе количественных и качественных методов диагностики авторы обосновали эффективность неформального образования для третичной социализации пожилых людей как основы их активного долголетия.
\end{abstract}

\title{
Non-Formal Education for the Older Generation Representatives as Factor of Their Active Ageing
}

\author{
Gordina O. V., Gordin A. I.
}

\begin{abstract}
The study aims to determine psychological and pedagogical conditions for organising non-formal education for the older generation representatives, which contributes to their active ageing. The authors have presented the main approaches to defining the concepts "non-formal education", "third age", "active ageing", "andragogical interaction", "tertiary socialisation", "higher public school". The article substantiates relevance of organising non-formal education to promote the older people's active ageing, determines learning process specificity in the third age, proves andragogical interaction effectiveness for the older people's tertiary socialisation as a basis for their active ageing. The authors have determined psychological and pedagogical conditions for organising non-formal education for the older generation representatives. Scientific novelty lies in developing an organisational and methodological system of education for the elderly in the context of trends in modern education development and constructing new educational reality on this basis as an implementable authors' project. As a result of the study, non-formal education importance for longevity of the elderly is confirmed, psychological and pedagogical conditions for organising this activity are identified. Using quantitative and qualitative diagnostic methods, the authors have proved nonformal education effectiveness for the older people's tertiary socialisation as a basis for their active ageing.
\end{abstract}

\section{Введение}

Актуальность. Устойчивой демографической тенденцией, заявившей о себе во второй половине XX века, является старение населения в ряде развитых стран, в том числе и в России. В настоящее время доля пожилых людей в структуре российского населения приближается к 25\% [6]. Демографы прогнозируют рост этих показателей [3]. Готовность общества к новой демографической реальности проявляется в формировании 
государственной политики, ориентированной на сохранение здоровья в зрелом возрасте, экономическую независимость, защищенность, социальную активность, в целом высокий уровень качества жизни представителей старшего поколения. Этот подход должен быть реализован в политике активного долголетия. В нашей стране на государственном уровне предпринимаются первые шаги в этом направлении, пока работа находится на стадии концептуализации. При этом уже сложились социально-педагогические практики в сфере неформального образования, культуры, добровольчества, способствующие созданию позитивного образа старости, укреплению социальной солидарности поколений, мотивации к активному долголетию людей третьего возраста. Само введение в научный дискурс понятия «третий возраст» [7], обозначающего новый период активной жизни человека, наступающий после его выхода на пенсию, является важной вехой в эволюции общественного сознания в отношении образа позитивного старения и активного долголетия.

Проблемой исследования является выявление потенциала неформального образования для содействия активному долголетию людей третьего возраста. Актуальность проблемы обусловлена наличием противоречий: между потребностью общества в обеспечении активного долголетия людей третьего возраста и отсутствием разработанного психолого-педагогического инструментария для сопровождения этого процесса; успешной, проверенной временем апробацией опыта неформального образования представителей старшего поколения и недостаточным осмыслением и слабой презентацией данного опыта для широкой педагогической общественности. Мы полагаем, что сфера неформального образования взрослых могла бы способствовать продлению достойной жизни людей третьего возраста, но приходится констатировать недостаточную разработанность правового, методологического, методического и технологического обеспечения неформального образования пожилых людей в современной России.

Задачами данного исследования являются:

- выявить специфику процесса неформального образования личности в третьем возрасте;

- определить эффективность андрагогического взаимодействия в пространстве неформального образования для третичной социализации пожилых людей как основы их активного долголетия;

- представить психолого-педагогические условия организации неформального образования, способствующие активному долголетию людей третьего возраста;

- обосновать эффективность неформального образования для третичной социализации пожилых людей как основы их активного долголетия.

Для решения поставленных задач нами использовались как теоретические (анализ философской, психолого-педагогической и социологической литературы), так и эмпирические методы исследования (качественные и количественные методы диагностики, социально-педагогический эксперимент по созданию и устойчивому функционированию Высшей народной школы для людей третьего возраста на базе Иркутского государственного университета).

Теоретической базой исследования послужили публикации российских и зарубежных авторов: Г. А. Ключарева [10], Т. М. Кононыгиной [5], В. Г. Доброхлеб [4], Н. П. Литвиновой [8], Дж. Мезирова [9], П. Ласлетт [7], Л. Н. Овчаровой, М. А. Морозовой, О. В. Синявской [6], которые рассмотрели различные аспекты неформального образования в третьем возрасте и проблему активного долголетия.

Практическая значимость исследования заключается в том, что представленные в статье психологопедагогические условия, способствующие активному долголетию людей третьего возраста, могут успешно тиражироваться в различных формах неформального образования взрослых, способствуя поддержанию социальной активности пожилых людей и улучшению их социального самочувствия.

\section{Специфика процесса неформального образования личности в третьем возрасте}

Активное долголетие принято рассматривать как «состояние социального, экономического, физического и психологического благополучия граждан старшего поколения, которое обеспечивает им возможность для удовлетворения потребностей, включение в различные сферы жизни общества и достигается при их активном участии» [Там же, с. 7]. Для достижения позитивной динамики по данным показателям необходима консолидированная работа целого ряда ведомств, курирующих такие сегменты в жизни общества, как здоровье и финансовое благополучие пожилых граждан, их профессиональную занятость и включенность в социально значимую деятельность.

Для разработки методологического и методического обеспечения активного долголетия россиян необходимо проведение междисциплинарных исследований. Существенный вклад в решение этой задачи может внести теория непрерывного образования, согласно которой образование должно сопровождать человека на всех этапах его жизни. В контексте изучения роли образования в активном долголетии личности главное место отводится неформальному образованию взрослых, располагающему комплексом методов и форм работы, оказывающих непосредственное влияние на личностное развитие обучающихся, их ценностные ориентации и субъективно ощущаемое качество жизни.

Неформальное образование для представителей старшего поколения ориентировано на поддержку обучающихся в процессе их адаптации к социально-экономическим реалиям современного российского общества. Неформальное образование также способствует преодолению возрастного кризиса, который сопровождается чувством невостребованности, переживанием явных негативных психофизических изменений. 
Сложившийся в общественном сознании отрицательный образ старости и старения тормозит позитивное развитие пожилого человека как личности, индивидуальности. Парадоксально, но стареющий человек, как правило, покорно принимает отведенную ему роль пассивного созерцателя собственного угасания. Между тем для пенсионера просто начинается новый этап жизни, в который он вступает с большим жизненным опытом. Речь идет о третичной социализации личности.

\section{Эффективность андрагогического взаимодействия в пространстве неформального образования для третичной социализации пожилых людей как основы их активного долголетия}

В наших работах мы уже отмечали, что «третичная социализация - это интеграция в общество взрослого человека, переживающего кризис прекращения трудовой деятельности, в связи с выходом на пенсию, изменением социального статуса и образа жизни» [3]. Критериями успешного протекания процесса третичной социализации, по нашему мнению, являются: «субъективная удовлетворенность качеством жизни, устойчивая мотивация и готовность к жизнетворчеству, просоциальная направленность личности» [Там же].

В контексте данных размышлений интерес для специалистов-андрагогов представляют труды американского ученого Дж. Мезирова, обогатившего теорию непрерывного образования понятием «перспектива», которая имеет особое значение для пожилых обучающихся. В работе «Трансформационные измерения обучения взрослых» [9] Дж. Мезиров обратил внимание на то, что в ходе обучения появляется новая интерпретация предыдущего опыта, которая открывает возможности для вхождения в общественную жизнь в новом качестве.

Российский социолог Т. М. Кононыгина на основе анализа исследований в области социализации пожилых людей определяет значимость образования на этом этапе жизни следующим образом: «Участие в различных образовательных мероприятиях помогает пенсионерам находить пути выхода из различных жизненных затруднений, обрести адекватное понимание себя, других людей и общества в целом, найти новые ориентиры в быстро меняющейся современной жизни...» [5, с. 10].

Таким образом, важно выстроить процесс неформального образования пожилых людей в контексте современных тенденций андрагогики и эффективно организовать андрагогическое взаимодействие как образовательный диалог.

\section{Психолого-педагогические условия организации неформального образования для представителей старшего поколения}

В качестве примера рассмотрим организационно-методическую систему неформального образования пожилых людей, созданную в условиях Высшей народной школы Иркутского государственного университета. Система включает в себя ряд компонентов: целевой, системообразующий, содержательный, организационнодеятельностный, оценочно-результативный.

Целевой компонент ориентирует всю деятельность Высшей народной школы на создание оптимальных условий для третичной социализации её слушателей.

Стержнем системообразующего компонента являются принципы образования взрослых: самостоятельности; совместной деятельности; опоры на опыт; индивидуализации; системности; контекстности; актуализации результатов обучения; развития образовательных потребностей; осознанности.

Содержательный компонент отражает приоритетные направления деятельности школы: учебное, рекреационное, художественно-творческое, информационно-аналитическое, волонтерское, обратная связь, самоуправление.

Психолого-педагогический инструментарий осуществления данных направлений деятельности представлен организационно-деятельностным компонентом системы, который включает в себя формы андрагогического взаимодействия: индивидуальные (социально-педагогическое сопровождение, письма, интервью и т.п.), групповые (обучение, общение, физкультура, художественное творчество, арттерапия), коллективные (научно-популярные лекции, встречи с представителями разных сфер жизни общества, досуг, выставки творческих работ слушателей и др.).

Естественно, что в неформальном образовании отсутствует процесс оценивания знаний, это прерогатива самих обучающихся. Но для оценки эффективности работы народной школы в целом в нашу систему введен оценочно-результативный компонент. Для получения обратной связи от слушателей применяются количественные и качественные методы диагностики. Критерии оценки качества работы школы мы уже называли выше, это критерии успешной третичной социализации: субъективная удовлетворенность качеством жизни, устойчивая мотивация и готовность к жизнетворчеству, просоциальная направленность личности [2].

В Высшей народной школе применяются технологии андрагогического взаимодействия, которые делятся на два вида:

- неимитационные (проблемная лекция, лекция вдвоем, проблемный семинар, устный журнал, дискуссия, педагогическая мастерская, мастер-класс, мозговой штурм, коммуникативный тренинг, «Философский стол», «Разговорное кафе»);

- имитационные (анализ конкретных ситуаций (далее КС); деловые, ролевые, учебные, исследовательские игры; театрализация). 
Все эти технологии отличает диалоговый, доверительный стиль общения, создание психологически комфортной образовательной среды. Одной из важных образовательных задач является формирование культуры творческого обмена знаниями, поощряющей взаимное доверие, самостоятельность поиска, стремление к новому, интерес к общей пользе, взаимодействие, увлеченность своим делом и креативность. Именно социальные горизонтальные связи лежат в основе образовательного процесса Высшей народной школы, деятельность которой является добровольческим служением всех участников обучающегося сообщества [3]. Основатель первой Высшей народной школы в современной России Н. П. Литвинова, анализируя социальные аспекты неформального образования, пишет: «...развитие образования взрослых способствует консолидации российского общества. Интегрируя присущие разным поколениям возможности, образовательные программы создают особую атмосферу познания окружающего мира, предпосылки сохранения духовного наследия и возрождения социального оптимизма россиян» [8, с. 19].

Таким образом, андрагогическое взаимодействие строится на диалоге, активной коммуникации с применением активных, интерактивных методов обучения. Пожилые люди очень нуждаются в коммуникации и приобщении к референтной группе. Жизненно важно найти друзей, единомышленников, ощутить свою принадлежность к обучающемуся сообществу, которое для многих переживающих период потерь (родных, друзей преклонного возраста) становится семьей. В неформальном образовании пожилых людей происходит преодоление возрастных барьеров.

\section{Обоснование эффективности неформального образования для третичной социализации пожилых людей как основы их активного долголетия}

Формированию качественной оценки уровня мотивации и готовности к жизнетворчеству, сформированности оптимистичного взгляда на жизненную перспективу способствует применение комплекса методов эмпирического исследования: биографический метод, интервьюирование, метод включённого наблюдения, метод незаконченного предложения, работа с документами. С помощью качественных методов исследования также изучались социальная направленность личности, её гражданская позиция, социальная активность, готовность к добровольчеству и социальному служению. В нашей работе применялись и количественные диагностические методики. Например, «Шкала оценки качества жизни» Н. Е. Водопьяновой [1].

Выборка составила 300 человек. Это те слушатели народной школы, которые посещают её занятия в течение 5 лет (с 2015 по 2020 годы). Отметим, что среди слушателей есть те, кто посещают школу более или менее 5 лет. Группа обучающихся в течение данного периода оказалась самой многочисленной, поэтому они находились в фокусе внимания нашего исследования.

Остановимся коротко на демографических характеристиках выборки, которые были получены в результате анкетирования слушателей, проведенного с применением авторской методики, разработанной преподавателями народной школы. Анализ полученных данных указывает на то, что наибольшую часть слушателей ВНШ составляют «молодые пенсионеры» в возрасте 55-65 лет (64,1\%). Процент людей предпенсионного возраста составляет 6,3\%. Существенно, что процент слушателей возрастной группы старше 65 лет составляет 29,6\%. Это в свою очередь указывает на сохранение познавательного интереса, социальной активности и «жизненных сил» данной возрастной группы. Около 80\% слушателей имеют высшее образование, у остальных - среднее специальное или среднее техническое.

В анкете слушатели ВНШ также указывали свою специальность, по которой они работали до пенсии или работают сейчас. Оказалось, что $32,8 \%$ опрошенных составили инженерно-технические работники различного профиля, $22 \%$ - группа работников экономической сферы (экономисты и бухгалтеры), несколько меньше $(17,5 \%)$ - группа педагогов, $11,2 \%$ слушателей составила группа медицинских работников различного профиля, следующая по численности группа в 3\% - представили физики. Среди других профессий отмечены юристы, химики, биолог-ботаник, биохимик, работник торговли, библиотекарь, картограф, математик, журналист, налоговый инспектор, фармацевт, менеджер, уборщица и другие.

Исходя из полученных данных, мы выяснили, что всего лишь 20\% опрошенных имеют гуманитарное образование. Не случайно в содержании учебной деятельности школы преобладает гуманитарное направление. Это и компенсация не полученных в свое время знаний, и получение актуальных современных знаний, и повышенный интерес к человеку как предмету познания, обусловленный возрастом респондентов.

Проведенное анкетирование слушателей также позволило изучить соотношение людей третьего возраста одиноких и проживающих с семьёй. Из 300 респондентов проживают вместе с семьёй 63\%, и 37\% респондентов проживают одни. Наличие семьи даёт человеку материальную и духовную поддержку родных, что в свою очередь формирует ощущение защищенности безопасности (при условии, если со стороны семьи нет угрозы для физического и психологического здоровья индивида). Менее защищёнными в этом плане себя чувствуют одинокие люди. Выяснилось, что 71,3\% слушателей, находясь на пенсии, не работают, а 28,7\% слушателей продолжают свою профессиональную деятельность. В ходе анкетирования удалось выявить мотивы прихода слушателей в ВНШ. Респонденты могли назвать 3 мотива. Основным мотивом является «потребность в современных знаниях, которые можно применить “здесь и сейчас”» $(85,4 \%)$, за ним в рейтинге находится мотив «потребность в общении» (46,5\%), высокие результаты получены при выборе мотива «поиск единомышленников» (26,8\%). Именно в эту группу вошли лидеры школы, составившие систему её самоуправления. 
Данные мотивы и потребности обусловлены социальным положением пожилых людей. Уход на пенсию это не только окончание профессиональной деятельности, но и постепенное ограничение социальных контактов, возможностей для саморазвития и самореализации. Полученные данные позволили нам дать следующую социально-демографическую характеристику слушателей Высшей народной школы:

- наибольшую долю слушателей составляют так называемые молодые пенсионеры в возрасте от 55 до 65 лет;

- большая часть слушателей имеет высшее образование, причём преобладают инженерно-технические и экономические специальности;

- больше половины слушателей проживают с семьёй (разного состава);

- продолжающих работать пенсионеров в 2,5 раза меньше, чем неработающих пенсионеров.

Таким образом, мы видим, что в ВНШ занимаются пожилые люди, имеющие разный социальный и материальный статусы.

С помощью качественных методов исследования изучалась социальная направленность личности, её гражданская позиция, социальная активность, готовность к добровольчеству и социальному служению.

Биографический метод. Глубинное интервью. О разрушении стереотипов и новом качестве жизни размышляет Нина Григорьевна, 66 лет: «В нашем обществе бытует мнение, что удел пенсионера - сидеть на лавочке во дворе или перед телевизором... Но это не для меня, не для моих друзей и знакомых. И когда мне вручили объявление о том, что в Иркутске открывается Высшая народная школа, не раздумывая сообщила об этом событии всем, кого знала, и мы пришли. Организаторы нашей школы предложили нам на выбор разные познавательные и интересные лекции, встречи с замечательными людьми нашего города, групповые занятия - психология, английский язык, компьютерная грамота, рукоделье и многое другое. А ещё школа подарила нам содержательное и доброжелательное общение. Мы все вместе стали ходить в иркутские театры, музеи, филармонию, органный зал, где происходит более близкое знакомство, это объединяет нас, начинают возникать группы по интересам».

О решении жизненных проблем как творческих задач и готовности меняться благодаря обучению в ВНШ рассказывает Галина Николаевна, 65 лет: «Объединившись в группу, мы решили идти на занятия психологией, потому что у всех семьи, дети, внуки. Много вопросов, трудно разрешаемых или вовсе не разрешаемых проблем. Хочется научиться находить контакт с молодёжью, стать более открытым, свободным. Иу нас многое получилось! Появилось более сердечное отношение друг к другу. Мы стали более мягкими, терпеливыми, многие из нас впервые смогли сказать себе: “Я есть!”».

О появлении опыта социального служения размышляет Татьяна Алексеевна, 70 лет: «В школе можно получить много новых знаний, найти друзей, заниматься любимым делом. Но главное: здесь мы учимся жить поновому. Многие из нас обрели радость в добровольчестве, участвуя в экологическом движении, курируя воспитанников детского дома или интерната для инвалидов и престарелых. Везде нас ждут. И это придает силы. Народная школа вселяет уверенность в себе, в завтрашнем дне».

Многочисленные глубинные интервью, которые были записаны студентами и преподавателями университета, метод включенного наблюдения позволили сделать определенный вывод: третичная социализация слушателей Высшей народной школы протекает успешно, поскольку по всем показателям выявлена положительная динамика.

Для оценки удовлетворенности субъективным качеством жизни слушателей была применена количественная диагностическая методика - опросник «Удовлетворённость качеством жизни» Н. Е. Водопьяновой. Цель данного метода - оценить степень общей удовлетворенности качеством индивидуальной жизни и выявить сферы жизнедеятельности, вызывающие наибольший дискомфорт или неудовлетворенность. Н. Е. Водопьянова выделяет следующие критерии качества жизни взрослого человека: удовлетворенность работой, удовлетворённость личными достижениями, удовлетворённость состоянием здоровья (физического и психологического), удовлетворённость общением с близкими людьми (родными, друзьями), удовлетворённость внутренней и внешней (социальной) поддержкой, удовлетворённость своими эмоциями, настроением и удовлетворенность окружающей социальной средой [Там же]. В результате удалось получить интегрированный показатель по каждому слушателю и по всей выборке в целом. Обобщенные результаты диагностического исследования с применением качественных и количественных методов исследования представлены в Таблице 1.

Таблица 1. Динамика уровня третичной социализации слушателей Высшей народной школы Иркутского государственного университета (2015-2020 г2.)

\begin{tabular}{|l|c|c|c|c|c|c|}
\hline \multirow{2}{*}{ Критерии } & \multicolumn{3}{c|}{ Уровень в \% (2015) } & \multicolumn{3}{c|}{ Уровень в \% (2020) } \\
\cline { 2 - 7 } & высокий & средний & низкий & высокий & средний & низкий \\
\hline $\begin{array}{l}\text { Субъективная удовлетворенность } \\
\text { качеством жизни }\end{array}$ & 8 & 57 & 35 & 26 & 60 & 14 \\
\hline $\begin{array}{l}\text { Устойчивая мотивация и готовность } \\
\text { к жизнетворчеству }\end{array}$ & 10 & 51 & 39 & 22 & 57 & 21 \\
\hline $\begin{array}{l}\text { Просоциальная направленность } \\
\text { личности }\end{array}$ & 24 & 36 & 40 & 37 & 39 & 24 \\
\hline
\end{tabular}

Диагностическое исследование выявило положительную динамику по всем критериям. Данные качественных и количественных методик коррелируют. Слушатели с показателями низкого уровня по критерию «Субъективная удовлетворенность качеством жизни» показали низкие результаты и по другим критериям 
третичной социализации. Для этой группы обучающихся реализуются индивидуальные программы социальнопедагогического сопровождения. Погружение в образовательный процесс Высшей народной школы позитивно влияет на третичную социализацию её слушателей. Школа имеет особый стиль жизни, где преподаватели и слушатели вместе пытаются разрешить жизненные проблемы, реализовать свои потребности и интересы, изменить свою жизнь, выстроить перспективу дальнейшего развития. Весь комплекс эффектов неформального образования в условиях ВНШ способствует субъективному ощущению социального, экономического, физического и психологического благополучия граждан старшего поколения. Социально ответственная позиция народной школы обеспечивает слушателям возможность удовлетворения потребностей в развитии, творческой самореализации, включения в различные сферы жизни общества, мотивирует пожилых людей к социальному служению, что в целом способствует их активному долголетию.

В 2020 году в рамках XXI Апрельской международной научной конференции по проблемам развития экономики и общества, которая проводилась в Высшей школе экономики (ВШЭ), была представлена «Концепция политики активного долголетия», которая должна стать предметом дискуссии в научном сообестве. Рабочая группа для экспертной разработки проекта Концепции активного долголетия в Российской Федерации на базе НИУ ВШЭ [6] обозначила приоритеты в формировании политики активного долголетия:

- здоровье граждан старшего поколения;

- обеспеченная и достойная жизнь в старшем возрасте;

- активность и участие в жизни общества.

Полагаем, что неформальное образование как инструмент просвещения, профилактики, реабилитации, развития человека третьего возраста может быть задействовано в работе по всем приоритетным направлениям. С 2012 года под эгидой ЕЭК ООН и генеральной дирекции Европейской комиссии по вопросам занятости, социальной политики и интеграции разрабатывается Индекс активного долголетия (ИАД), который должен стать инструментом для измерения использования потенциала пожилых людей для активного и здорового долголетия в разных странах. С 2020 года ИАД рассчитывается в России на основе методики, экспериментально разработанной Институтом социальной политики НИУ Высшей школы экономики. Показатели, по которым измеряется ИАД: занятость; вовлеченность в жизнь общества; независимость; здоровье; защищенность; благоприятная среда. Обращает на себя внимание подход авторов к пожилым людям как объектам включения в деятельность, обслуживания, защиты. Авторский коллектив, к сожалению, также находится во власти стереотипа негативного отношения к старению как периоду пассивного угасания. Полагаем, что вместо показателя «Включенность...» целесообразнее было бы ввести показатель «Создание условий для участия в жизни общества», более точно отражающий ситуацию, в которой протекает процесс третичной социализации пенсионеров. Они не нуждаются во «“включении” в жизнь общества», их надо оградить от изоляции. Старшие поколения, имеющие в целом значительный опыт участия в общественной жизни, не утратившие чувство социальной солидарности, могут и готовы быть активной созидательной силой общества и включить в эту деятельность другие возрастные группы.

Хотелось бы отметить, что в Концепции активного долголетия есть раздел «Активность и участие в жизни общества», в котором отражена активная позиция самих пенсионеров:

- реализация концепции «образование в течение всей жизни»;

- развитие волонтерского движения;

- досуговая, общественная и гражданская активность;

- укрепление межпоколенных взаимодействий.

Все указанные в данном разделе направления деятельности являются отражением уже сложившейся реальной практики погружения людей третьего возраста в процесс неформального образования, их собственной социальной активности. Важно, что рабочая группа учла это обстоятельство. Хотелось бы надеяться, что в процессе формирования российской политики активного долголетия будет сделан акцент не только на сохранении здоровья, финансовой поддержке и социальном обслуживании (что, безусловно, важно), но и на профилактике негативного старения посредством создания условий для развития, творческой самореализации, жизнетворчества представителей старшего поколения.

\section{Заключение}

Таким образом, мы пришли к выводам, которые соответствуют общему смыслу работы.

1. Неформальное образование в третьем возрасте выполняет нетрадиционные для учебной деятельности функции - оно способствует активному долголетию. Формируемое образовательное сообщество создаёт условия для появления референтной группы, улучшения физического здоровья и отношений в семье, личностной и социальной самореализации обучающихся, социального служения, формирования позиции субъекта жизнетворчества. Целью такого образовательного процесса может быть успешная третичная социализация личности как основа активного долголетия.

2. Неформальное образование человека предпенсионного и пенсионного возрастов должно осуществляться в условиях устойчивого образовательного сообщества (Высшая народная школа, Университет третьего возраста и др.), представляющего собой стабильный коллектив слушателей, коммуникации в котором формируют чувство защищенности, востребованности, причастности к важной референтной группе. Андрагогическое 
взаимодействие в Высшей народной школе и народном университете строится на диалоге, активной коммуникации с применением активных, интерактивных методов обучения. Неформальное образование является полем приложения жизненных сил субъектов образования третьего возраста в разных сферах деятельности (учебное направление, рекреационное, художественно-творческое, информационно-аналитическое, волонтерское, самоуправление и др.), что способствует формированию более оптимистичного взгляда на жизненную перспективу у пожилого человека, успешному протеканию процесса его третичной социализации и активному долголетию.

3. Организационно-методическая система образования людей пожилого возраста в контексте тенденций развития современного образования воплотилась в образовательном пространстве Высшей народной школы Педагогического института ИГУ. Система включает в себя ряд компонентов: целевой, системообразующий, содержательный, организационно-деятельностный, оценочно-результативный. Эти компоненты, выполняя специфические функции, в совокупности создают целостный процесс андрагогического взаимодействия как новую образовательную реальность.

Модель организации неформального образования людей третьего возраста в рамках данной системы представляет собой сетевой проект во главе с вузом как научным, организационным, методическим ядром. Образовательное пространство состоит из горизонтальных связей, соединяющих представителей педагогической общественности, искусства, здравоохранения, третьего сектора, власти, бизнеса, СМИ. Содержание занятий в таком образовательном учреждении отличает актуальность, доступность, вариативность. В процессе занятий интенсивно актуализируется имеющийся и формируется новый жизненный опыт обучающихся как основа их дальнейшего развития и жизнетворчества. Неформальное образование, осуществляемое в условиях образовательного сообщества Высшей народной школы, Народного университета, мотивирует и готовит слушателей к социальному служению, создает условия для участия в волонтерской деятельности, предполагает адресную психолого-педагогическую поддержку самим обучающимся, находящимся в трудной жизненной ситуации.

4. Неформальное образование не сможет внести коррективы в такие внешние по отношению к человеку факторы, как политическая, социально-экономическая, экологическая ситуация в регионе и т.п. Оно оказывает влияние на позицию взрослого человека в отношении этих и других факторов, определяющих качество его жизни. Неформальное образование, осуществляемое в условиях активного андрагогического взаимодействия, способствует пробуждению и актуализации внутренних ресурсов личности, превращая жизненные проблемы в творческие задачи, требующие вдумчивого и деятельного решения. Эмпирическое исследование уровня третичной социализации слушателей Высшей народной школы Иркутского государственного университета (2015-2020 гг.) позволило выявить положительную динамику по всем определенным нами критериям: субъективная удовлетворенность качеством жизни; устойчивая мотивация и готовность к жизнетворчеству; просоциальная направленность личности. Позиция субъекта жизнетворчества представляется вершиной, важнейшим эффектом неформального образования взрослых, который может способствовать активному долголетию представителей старшего поколения.

Полагаем, что дальнейшим перспективным направлением педагогического исследования в сфере неформального образования пожилых людей является разработка и реализация программ, посвященных информационной безопасности, развитию навыков критического мышления, избирательности в отношении информации, размещенной в средствах массовой коммуникации.

\section{Источники | References}

1. Водопьянова Н. Е. Оценка удовлетворенности качеством жизни // Практикум по психологии здоровья: учеб.-метод. пособие / под ред. Г. С. Никифорова. СПб.: Питер, 2005. С. 148-156.

2. Гордина О. В., Гордин А. И. Высшая народная школа как пространство самоактуализации человека третьего возраста // Педагогика. Вопросы теории и практики. 2020. Т. 5. Вып. 5. С. 582-587.

3. Гордина О. В., Гордин А. И. Концептуальная модель современной Высшей народной школы для людей третьего возраста [Электронный ресурс] // Современные проблемы науки и образования. 2015. № 4 . URL: http://www.science-education.ru/127-20497 (дата обращения: 19.04.2021).

4. Доброхлеб В. Г. Старение населения как фактор модели демографического перехода на примере современной России // Социологический альманах. 2012. № 3. С. 67-73.

5. Кононыгина Т. М. Герагогика: пособие для тех, кто занимается образованием пожилых людей. Орел: Красная строка, 2006. 166 с.

6. Концепция политики активного долголетия: науч.-методол. доклад к XXI апр. междунар. науч. конф. по проблемам развития экономики и общества (г. Москва, 2020 г.) / под ред. Л. Н. Овчаровой, М. А. Морозовой, О. В. Синявской; Нац. исслед. ун-т «Высш. шк. экономики». М.: Изд. дом Высш. шк. экономики, 2020. 40 с.

7. Ласлетт П. Что такое Старость? Вариации во времени и между культурами / под ред. Г. Казелли и А. Лопес. Оксфорд: Издательство Оксфордского университета, 1996. 128 с.

8. Литвинова Н. П. Тенденции и перспективы развития Высших народных школ // Человек и образование. 2010. № 4. С. 15-19.

9. Мезиров Дж. Трансформационные измерения обучения взрослых. Сан-Франциско: Джосси-Басс, 1991.

10. Непрерывное образование в политическом и экономическом контекстах / отв. ред. Г. А. Ключарев. М.: ИС РАН, 2008. 400 c. 


\section{Информация об авторах | Author information}

RU Гордина Ольга Васильевна ${ }^{1}$, к. пед. н., доц.

Гордин Александр Иннокентьевич ${ }^{2}$, к. пед. н., доц.

1,2 Иркутский государственный университет

EN Gordina Olga Vasilevna ${ }^{1}, \mathrm{PhD}$

Gordin Aleksandr Innokentevich ${ }^{2}, \mathrm{PhD}$

${ }^{1,2}$ Irkutsk State University

1'g.o.v.2018@mail.ru, 2a-gordin58@mail.ru

\section{Информация о статье | About this article}

Дата поступления рукописи (received): 10.05.2021; опубликовано (published): 30.06.2021.

Ключевые слова (keywords): неформальное образование; представители старшего поколения; активное долголетие; психолого-педагогические условия; организационно-методическая система образования; non-formal education; older generation representatives; active ageing; psychological and pedagogical conditions; organisational and methodological system of education. 